\title{
3D printed prototyping tools for flexible sheet metal drawing
}

\author{
Peter Frohn-Sörensen ${ }^{1}$ (1) $\cdot$ Michael Geueke $^{1}$ (D) $\cdot$ Tadele Belay Tuli $^{2}$ (D) Christopher Kuhnhen $^{1}$ (D) Martin Manns $^{2}$ (D) \\ Bernd Engel ${ }^{1}$ (D)
}

Received: 28 December 2020 / Accepted: 20 May 2021 / Published online: 28 May 2021

(C) The Author(s) 2021

\begin{abstract}
Due to the change from mass production to mass personalized production and the resulting intrinsic product flexibility, the automotive industry, among others, is looking for cost-efficient and resource-saving production methods to combining global just-in-time production. In addition to geometric manufacturing flexibility, additive manufacturing offers a resource-saving application for rapid prototyping and small series in predevelopment. In this study, the FDM process is utilized to manufacture the tooling to draw a small series of sheet metal parts in combination with the rubber pad forming process. Therefore, a variety of common AM polymer materials (PETG, PLA, and ABS) is compared in compression tests, from which PLA is selected to be applied as sheet metal forming die. For the rubber pad forming process, relevant processing parameters, i.e., press force and rubber cushion hardness, are studied with respect to forming depth. The product batch is examined by optical evaluation using a metrological system. The scans of the tool and sheet metal parts confirm the mechanical integrity of the additively manufactured die from polymer and thus the suitability of this approach for small series in sheet metal drawing processes, e.g., for automotive applications.
\end{abstract}

Keywords Additive manufacturing $\cdot$ Forming flexibility $\cdot$ Rubber pad forming $\cdot$ Sheet metal forming $\cdot$ Rapid tooling

\section{Introduction}

Over the past decades, consumer demand led to the transformation from mass production to mass personalized production, where on-demand high output and flexibility, as well as customization, led to an increase in product variety (see Fig. 1).

In this context, various types of flexibility such as machine (various operations performed without set-up change) or product (ease of introducing products into an existing product mix) flexibility are differentiated. The capacity to quickly adapt to new, partly unknown requirements may be achieved by designing reconfigurable manufacturing systems with fast exchange reconfiguration modules [2]. However, the achievable agility is directly dependent on how fast and easy

Michael Geueke

Michael.Geueke@uni-siegen.de

1 Chair of Forming Technology, Institute for Production Technology, University of Siegen, Breite Straße 11, 57076 Siegen, Germany

2 Chair of Production Automation and Assembly, Institute for Production Technology, University of Siegen, Breite Straße 11, 57076 Siegen, Germany reconfiguration modules become usable in the manufacturing system. The availability of inexpensive additive manufacturing systems may provide a relevant contribution to tackling the high complexity of layout design in reconfigurable manufacturing systems [3] by providing an easily available, close to process source of reconfigurable tool components.

Customer integration and personalization remain as major issues with regard to low-cost mass production. In order to reconcile large-scale manufacturing and personalized diversification, quality, variety and reduction of cost and time are restrictive factors given by conventional manufacturing methods [1]. Customization with respect to manufacturing flexibility is commonly applied to processes such as welding and machining, but still challenging or insufficient concerning forming. For production of large lot sizes, conventional forming techniques are fast and accurate but insufficient when producing variants, which is due to expensive tooling. To ensure mass customization and personalization in metal forming, flexibility plays a vital role $[4,5]$.

FROHN-SÖRENSEN et al. introduce a flexible manufacturing chain for an incremental bending process, where individualization is achieved by the variation of different profile shapes for the same forming tool [6]. Including the customer's individual anthropometry, Schiller et al. process a freeform 


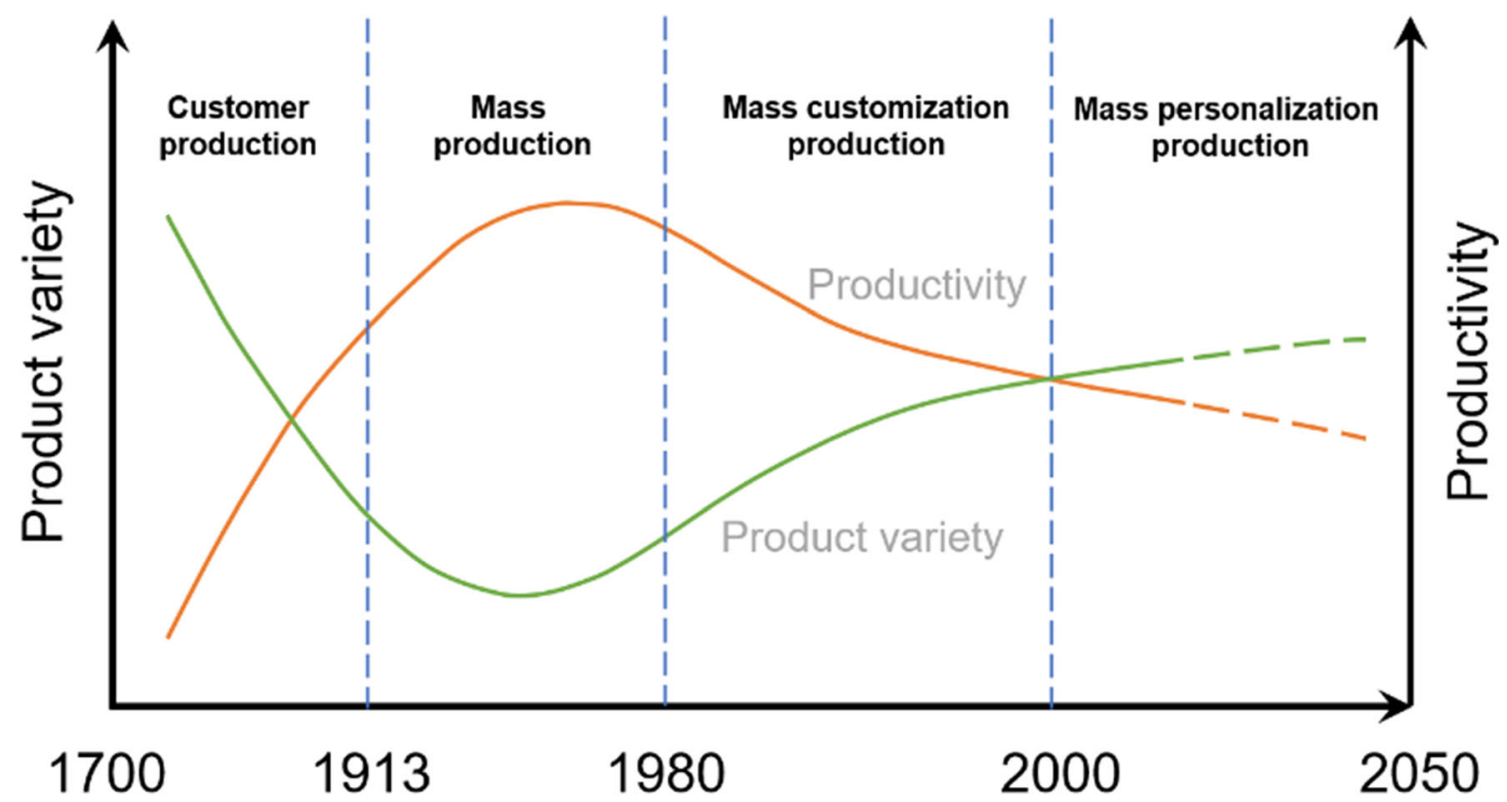

Fig. 1 Evolution of production paradigms as associated with the four industrial revolutions, according to WANG et al. [1]

bending method, where an individualized chair is manufactured automatically according to the body measurements of the customer [7]. Selmi and BeLhadjSALAh focus on multipoint hydroforming with a flexible elastomeric die to reduce tool costs and to maximize product variability for a specific tool application [8].

Most often, the variation of the tools in forming processes and therefore the individualization of the products require either a large infrastructure or high tooling costs to achieve a degree of freedom (DoF) for flexibility [4]. In order to enable economical product manufacturing, flexible tool production is required to efficiently achieve manufacturing high number of variants.

Rubber pad forming (RPF) is a well-established flexibledie forming process in the automotive, aerospace, energy, and food industries. It allows manufacturing a variation of complex shapes [9]. RPF has been developed at the DougLAs AIRCRAFT COMPANY in the United States of America during the Second World War. The tool comprises a rigid die (top) and an elastic rubber pad (bottom), which can either be attached in a negative (female) or positive (male, a.k.a GUÉRIN) process setup [10] (cf. Fig. 2)

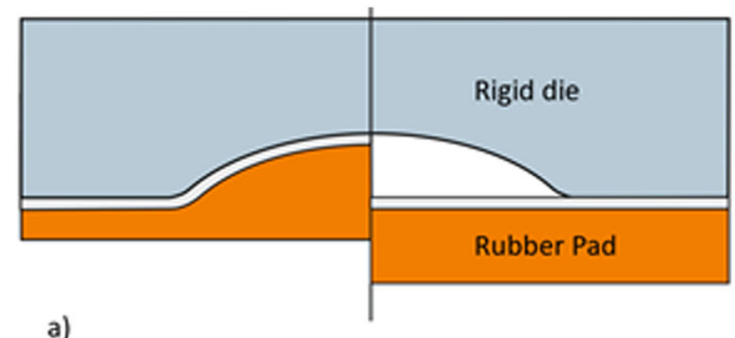

a)
In addition, the male process variant has been improved subsequently by a blank holder, commonly denoted the MARFORM process (by the GLen L. MARTIN Company), to overcome the problem of wrinkles in the flange area, especially when forming parts with deeper cavities [11]. When applying force on the rigid die, the elastic rubber pad is deformed in the blank space of the rigid tool. The blank metal is squeezed in the blank section, which can be stated as a deep drawing and redrawing process. Moreover, the ductile behavior of the rubber pad ensures a good friction coefficient.

Compared to conventional sheet metal forming processes, advantages of RPF processes are low cost (tooling), dimensional accuracy, high flexibility, and short lead-time for tooling and part, as well as good surface quality of the formed parts, especially for small and medium batch size production [12]. Summing up those advantages, RPF could be an option for mass personalization, where a low volume production is required due to the high number of individual product variants [13-15]. Since the RPF process consists of a flexible rubber pad and a form shaping die, the required product geometry is specified by the geometry of the die. For enhancing geometrical DoF and flexibility of the forming process, the die can

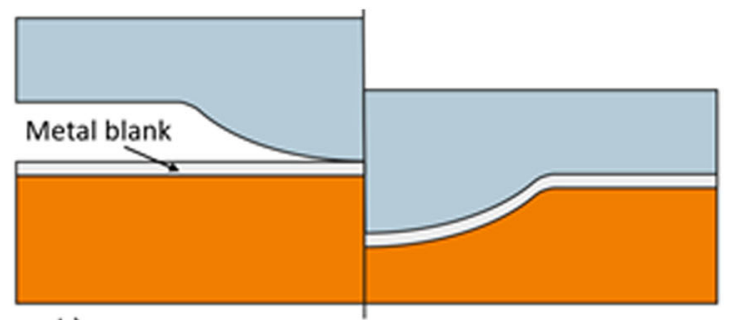

b)

Fig. 2 Tool setup for a negative (female) and $\mathbf{b}$ positive (male) rubber pad forming process 
either be adjusted flexibly or manufactured individually for each desired single shape, where the last option is usually correlated with high tooling costs and lead-time $[13,15,16]$.

To overcome these drawbacks, additive manufacturing (AM) techniques such as fused deposition modeling (FDM) may be applied to the die manufacturing process, as their geometrical limitations are most likely to be restricted to the size of the building chamber. Additionally, AM enables a high level of geometrical freedom and flexibility due to its process [17]. Over the past decade the impact of AM has increased rapidly, next to their process and lead-times. Therefore, AM is highly desirable to manufacture so called rapid tooling for forming processes. The variance and integrity of AM base materials is a promising assortment for different applications in the design and manufacturing sector, as their mechanical properties have improved drastically over the past decade [18]. Hence, AM is a promising alternative to the traditional manufacturing techniques for producing sheet metal forming dies. As one of the most common AM techniques, Fused Deposition Modeling (FDM) is applicable to a wide range of thermoplastics filaments such as polylactic acid (PLA), nylon or acrylonitrile butadiene styrene (ABS), which may be improved by fibers or metallic particles additionally. NAKAMURA et al. improved Vbend tools by reinforcing metal steel bars to enhance dimensional accuracy and mechanical performance of FDM printed PLA [19]. DURGUN investigates AM printed polycarbonate dies in a sheet metal stamping process to reveal the dimensional wear behavior and conformance for up to 101 parts [20]. SCHUH et al. examine a two-sided AM punch model from PLA to inspect the formability of automotive sheet metal blanks [21]. They conclude a simulative and experimental approach for the wear and deformation behavior of the forming dies for up to 23 parts.

Despite, or perhaps because of the growing population and the increase in demand for resources and energy consumption, the attitude of humankind has changed significantly toward a more sustainable way of life. Natural and bio-based materials like PLA are promising to reduce the economic impact in the manufacturing industry $[22,23]$. In this context, in order to reduce tooling costs and, at the same time enhance the flexibility of the whole tooling, an RPF process is implemented with an FDM printed drawing die in this study. A systematic evaluation of the forming die, as well as the formed sheet metal parts, may indicate the cyclic performance of polymer based materials. The motivation for this paper is to combine the advantages of the RPF and AM technology and to investigate a flexible and customizable process ("AM-RPF") for forming of sheet metal blanks, particularly for small batch sizes.

\section{Methodology}

The feasibility of additively manufacturing a die for sheet metal forming from polymer materials is the central objective of this investigation. Initially, a target geometry of dome shape model is created in CAD using an automotive standard drawing sheet metal. Moreover, a suitable AM polymer is required, which (1) can be $3 \mathrm{~d}$ printed by offering economic benefits within the application context, (2) withstands the occurring static compressive loads during stamping, and (3) shows a ductile deformation behavior. Based on this, preliminary material tests are conducted to choose the appropriate manufacturing technology. The experiments on rubber pad forming are conducted on a universal testing machine to assure precise evaluation of force over travel signals corresponding to the forming operation. Finally, an optical scanner is used to analyze the quality and formability of the dome shaped sheet metal surface of the herein objected exemplary product shape.

\subsection{DESIGN}

For the forming experiments, a tooling is designed to apply the rubber pad forming process to a universal testing machine. The facility provides a maximum press force application of $250 \mathrm{kN}$ and intrinsic evaluation of force and displacement. Similar to NIKNEJAD et al., the "female" type rubber pad forming process (cf. Fig. 2a) is applied to the forming of a dome shaped geometry from sheet metal [24]. The cavity of the tool describes a dome geometry and features a fillet radius to the flange area of $2.5 \mathrm{~mm}$. Next to the additively manufactured die from the favored polymer material, the shore hardness of the rubber pad needs to be considered as well, as its enclosing restrainer and the adaptation to the machine. The CAD of the assembly utilized in this work is shown in Fig. 3.

Due to its universal applicability, the restrainer is subtractively made by milling from conventional tool steel grade 1.2312. The restrainer encloses a rubber pad of the outer dimensions of $115 \times 115 \mathrm{~mm}^{2}$ and is made from polyurethane, which can be adjusted in hardness according to the mixture ratio of the cast compounds. For the present investigation, 40 , 60 , and 80 hardness Shore rubber pads are cast with a thickness of $20 \mathrm{~mm}$. The forming die is additively manufactured. In the type I rubber pad forming process, the rubber pad is compressed and expands into the cavity of the die, thus stretch drawing the sheet metal.

\subsection{AM MATERIALS}

Considering availability, FDM is a widespread additive manufacturing technology. A variation of thermoplastic filament materials is covered within this study in order to find a good applicability to sheet metal forming dies. Polyethylene terephthalate modified by glycol, PETG, is a common FDM material used in diverse applications [25]. In general, strength, durability and reasonable workability are associated with this material. Stiff mechanical properties are also associated with polylactic acid (PLA) [26] which, additionally, allows a 
Fig. 3 Cut view of the CAD model of the AM-RPF process: rubber pad forming with an additively manufactured die, assembled on a universal testing machine

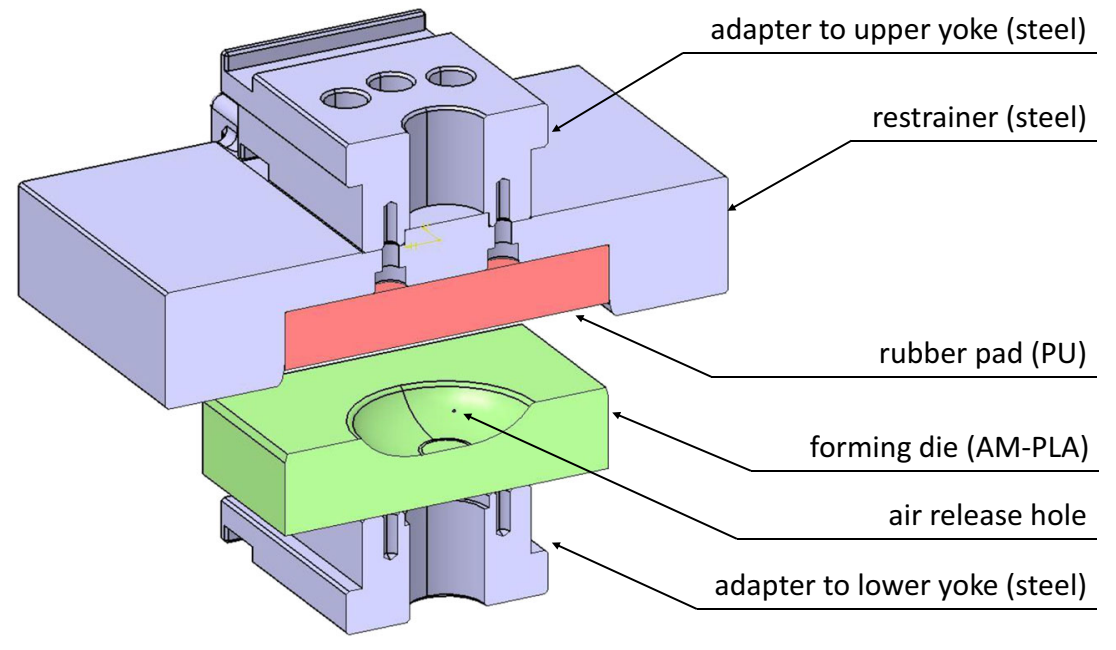

biological decomposition after use [27]. Acrylonitrile butadiene styrene (ABS) is another thermoplastic polymer which is commonly applied in FDM. In the present study, the following parameters are adjusted in the additive manufacturing process according to Table 1.

For the feasibility study of AM-materials in sheet metal forming dies, the compressive properties of the materials described in Table 1 are investigated. Therefore, cylindrical test specimens are additively manufactured from the materials, (see Fig. 4) and subjected to destructive compression tests, according to EN ISO 604:200.

Moreover, to gather information about aging influence, the materials are tested two days after fabrication and, for the most promising materials regarding the application as forming dies, after 20 days. With this approach, the time span associated with typical readiness of tools in a production plant is estimated with regard to manufacture of tools until their operation in production. Three repetitions are conducted for each individual test setup from which a representative curve is displayed for each material in Fig. 5.

Since thermoplastics reveal a hygroscopic behavior $[28,29]$, the specimens are kept in sealed bags after printing. Compared to the tests carried out with two days old specimens, the later tests reveal slightly higher strain-related mechanical properties after 20 days, which indicates a decrease in elastic stiffness. Therefore, the hereby presented polymers beneficially support their utilization as tool materials in a just-in-time production environment.

Two distinct mechanical behaviors are obtained from the resulting flow curves. A characteristic compressive yield stress maximum is observable from the stressstrain curves of PETG and PLA while a continuously increasing stress over strain function without a local distinct yield stress maximum is obtained from the ABS polymer. With regard to their aging, the materials show slight variations in the mechanical properties. For each material, the compressive mechanical parameters are evaluated quantitatively in Table 2 from the repetitions of the two days old specimen. For ABS, yield stress is assessed at 5\% compression, as no characteristic maximum is present from the tests because of the monotonous increase of stress over strain, cf. Fig. 5, even if higher compression is tested.

For the application in forming tools, the three key material properties of interest are,

Table 1 FDM manufacturing parameters for pretest specimens with $90^{\circ}$ alternating printing path

\begin{tabular}{|c|c|c|c|c|c|}
\hline \multicolumn{2}{|l|}{ Parameter } & \multirow{2}{*}{$\begin{array}{l}\text { PLA } \\
0.4\end{array}$} & \multirow{2}{*}{$\begin{array}{l}\text { PETG } \\
0.4\end{array}$} & \multirow{2}{*}{$\begin{array}{l}\mathrm{ABS} \\
0.4\end{array}$} & \multirow{2}{*}{$\begin{array}{l}\text { Explanation } \\
\text { Diameter of extrusion nozzle }\end{array}$} \\
\hline Nozzle diameter & {$[\mathrm{mm}]$} & & & & \\
\hline Fixed layer height & {$[\mathrm{mm}]$} & 0.1 & 0.2 & 0.2 & Thickness of each layer \\
\hline Fixed first layer height & {$[\mathrm{mm}]$} & 0.2 & 0.2 & 0.2 & Thickness of first layer \\
\hline Extruder temperature & {$\left[{ }^{\circ} \mathrm{C}\right]$} & 210 & 250 & 245 & Temperature of the nozzle during printing \\
\hline Platform temperature & {$\left[{ }^{\circ} \mathrm{C}\right]$} & 55 & 90 & 70 & Temperature of the printing bed \\
\hline Printing speed & {$[\mathrm{mm} / \mathrm{s}]$} & 45 & 45 & 40 & Speed during printing \\
\hline Infill density & {$[\%]$} & 100 & 100 & 100 & Interior solidity of the model \\
\hline Shell count & & 3 & 3 & 3 & Number of shells to contour the cross-sectional area \\
\hline
\end{tabular}




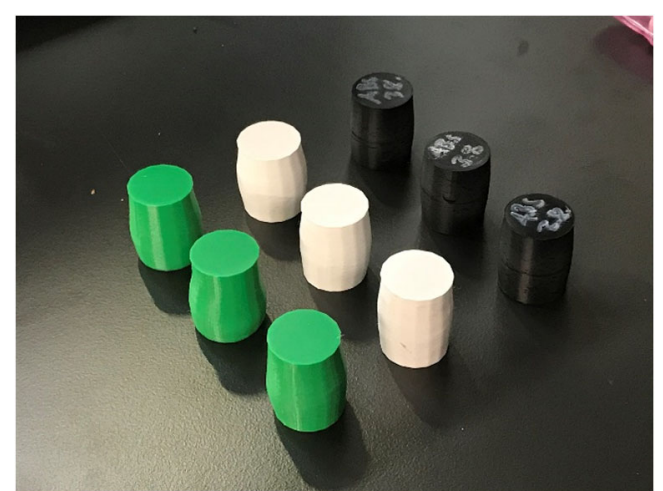

Fig. 4 FDM AM material variation: PETG (green), PLA (white), and ABS (black). Cylindrical specimens are subjected to compression tests to evaluate the mechanical properties of the material

1) Stiffness, related to the compressive elastic modulus $E_{\mathrm{C}}$ determines the relationship between the die geometry and the product and can be compensated in the design phase. In general, a stiffer tooling is related to higher forming accuracy.

2) Strength gives the maximum feasible load of the forming die. Therefore, a high strength AM material is favorable.

3) Brittleness strongly increases the risk of tool breakage. As the effective gradients of contact pressure can be estimated from analytic considerations, local maxima in the practical application could overload the capacities of the material. On the other hand, with reasonable ductility, an overloaded tool would be rather partially deformed instead of break, which would cause initial run in effects.

With regards to the three aspects raised above, PETG and PLA show promising mechanical properties when subjected to compressive load. Considering applications such as forming tools of small quantities, PLA is selected for the application of this investigation due to its universal availability. According to the CAD geometry shown in Section 2.1, the die is additively manufactured on a Creality Ender 3 Pro from
Table 2 Mechanical material parameters under compressive load of the investigated additively manufactured polymer materials

\begin{tabular}{lllll}
\hline Material & $E_{\mathrm{c}}[\mathrm{MPa}]$ & $\sigma_{\mathrm{y}}[\mathrm{MPa}]$ & $\varepsilon_{\mathrm{cy}}[\%]$ & $\sigma_{5 \%}[\mathrm{MPa}]$ \\
\hline PETG & $1880 \pm 23$ & $75.2 \pm 0.3$ & $5.0 \pm 0.1$ & - \\
PLA & $1688 \pm 10$ & $67.3 \pm 0.4$ & $5.2 \pm 0.1$ & - \\
ABS & $1497 \pm 8$ & - & - & $51.4 \pm 0.5$ \\
\hline
\end{tabular}

PLA, see Fig. 6. The parts are printed in multiple repetitions for the practical experiments (Section 3.1) according to the parameters of Table 1.

\subsection{RUBber PAD MATERIAL}

Polyurethane (PUR) rubber pads are cast with varying components to achieve a variation in shore-A hardness. A variation of mixing ratios of Sika PUR resin U1404 is applied according to the manufacturer's instructions to obtain three different degrees of shore-A hardness $(40,60$, and 80$)$, which are applied to the rubber pad forming process during the pretests. The required mixtures are cast directly in the restrainer with a thickness of $20 \mathrm{~mm}$ each to achieve good geometrical correspondence for the process. After seven days, the cured rubber pads are extracted from the restrainer and implied to the forming process.

\section{$\mathbf{2 . 4}$ SHEET METAL MATERIAL}

A standard automotive body deep drawing sheet metal of DC03 grade and thickness of $0.7 \mathrm{~mm}$ is introduced to the AM-RPF process. Blanks of $80 \times 80 \mathrm{~mm}$ size are cut for the practical experiments. For comprehensiveness, the mechanical parameters of this sheet metal material are evaluated by uniaxial tensile tests, which are summarized in Table 3.
Fig. 5 Mechanical properties of different AM polymers under compression with respect to the influence of aging. Graphs are given as average of test repetitions

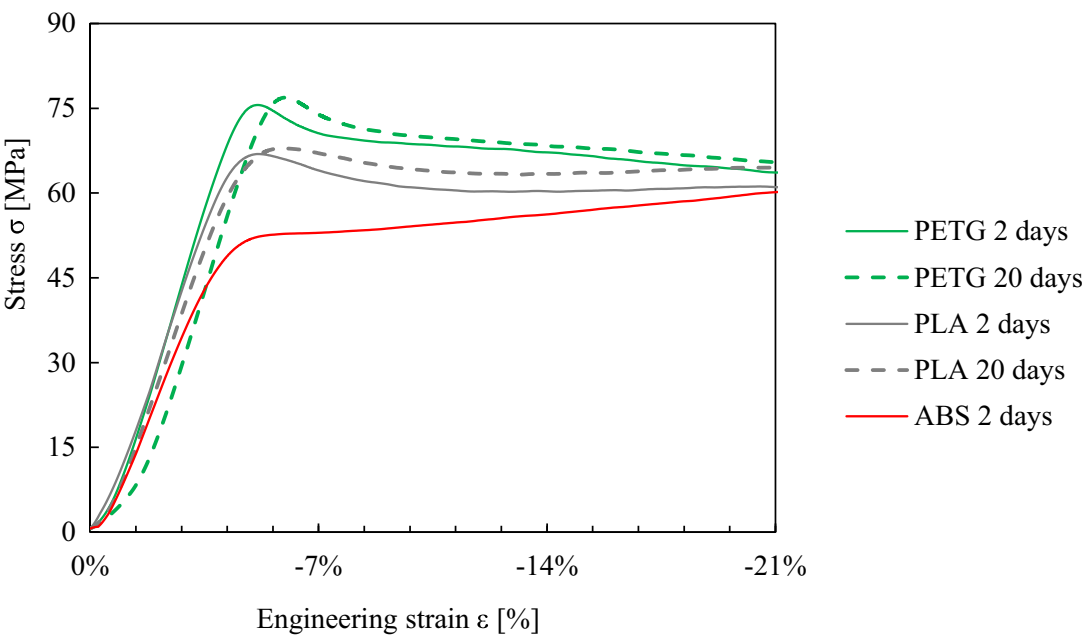


Fig. 6 Additively manufactured forming die from PLA in a FDM printing layer resolution of 0.1 $\mathrm{mm}$. a Showing geometrical overview and $\mathbf{b}$ detail for $0.1 \mathrm{~mm}$ printing resolution and air release hole

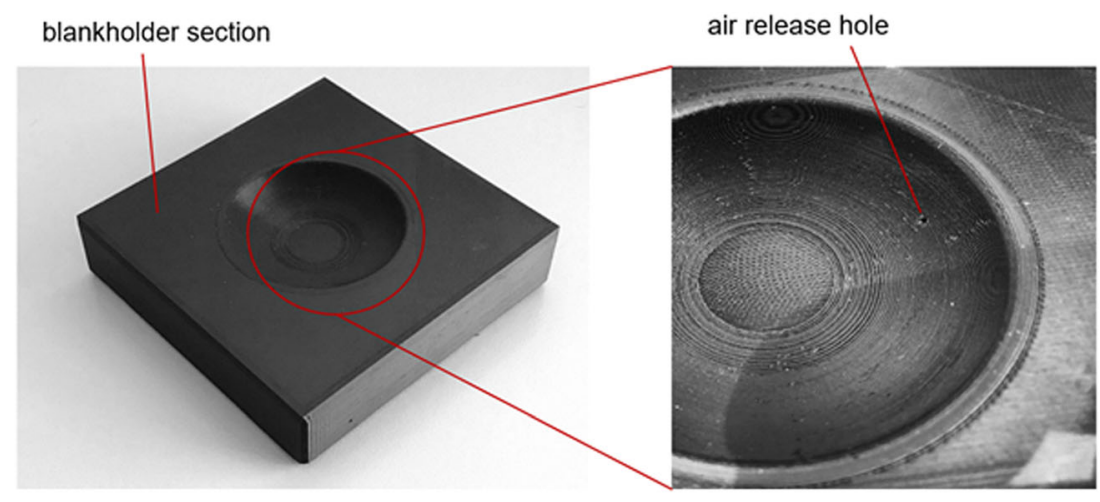

\subsection{FORMING EXPERIMENTS}

The experimental procedure according to the test assembly shown in Fig. 3 is structured in two parts. First, the amount of plastic deformation of the sheet metal caused by the loaded rubber pad as a function of applied forming force is of key interest. Therefore, the applied press load is raised in successive steps of $25 \mathrm{kN}$ and the geometry resulting from each step is evaluated. Next, the RPF process is tested with a variety of hardness of the rubber pad in between 40,60, and 80 degrees Shore-A hardness. The hardness is expected to show a compliant increase of the required forming force. Harder rubber pads generally require significantly higher press force but are sufficient to suppress the formation of wrinkles [11, 30, 31].

In the second approach, a fresh die is introduced to the AMRPF process under application of the before evaluated suitable forming parameters with regard to forming force and rubber pad hardness. Repetitive forming iterations are conducted to provide information on geometric stability of the AM die with respect to the areas of highest contact stress, i.e., the blank holder area and, in particular, the drawing radius. Surface scans provide statistical information about manufacturing accuracy and any attrition of the additively manufactured tooling.

\subsection{MEASURING DEVICE}

The metrology system gom ATOS Core 200 is used to measure the $3 \mathrm{~d}$ printed forming dies. The optical measurement of this system bases on the principle of photogrammetry to scan the topological parameters of an object. These data can be integrated subsequently into further analyses, such as the deformation measurement by gom ARAMIS. Both systems are available at the Centre for Smart Production Design Siegen

Table 3 Tensile mechanical properties of an $0.7 \mathrm{~mm}$ DC03 sheet metal applied in this study

\begin{tabular}{lll}
\hline$R_{\mathrm{e}}[\mathrm{MPa}]$ & $R_{\mathrm{m}}[\mathrm{MPa}]$ & $n[-]$ \\
\hline $181 \pm 3$ & $310 \pm 1$ & $0.105 \pm 0.01$ \\
\hline
\end{tabular}

(SmaPS) at the University of Siegen, where the present study was conducted.

The system has been validated by the manufacturer according to the technical guideline VDI 2634. The calibration parameters utilized for the present experiments are listed in Table 4.

The calibration deviation was 0.052 pixel and thus under the maximum value of 0.100 pixel. The results of the projector calibration were a gap of 0.038 pixel in accordance with a maximum value of 0.250 pixel. The gom ATOS Core 200 measuring head is therefore reliable for the following measurement procedure.

The software for the measurement process is gom Scan 2019. For the measurement analysis, gom Correlate 2020 is used.

\section{Results}

\subsection{EMPIRICAL DETERMINATION OF PROCESS PARAMETERS}

The experiments confirm the feasibility of operating AM tools in the female type RPF process for forming products from sheet metal of automotive body grade and thickness.

For this study, the process parameters that are necessary to form a spherical dome geometry from DC03 sheet metal in the rubber pad forming process are determined in an empirical approach. Initially, the applied press force is increased successively by $25 \mathrm{kN}$ steps in order to investigate the filling of the cavity throughout the rubber pad forming process. As a softer pad in general would reveal the advantages of a lower necessary process force for the RPF process, a 40 Shore polyurethane pad is initially utilized (see Fig. 7). At a process force of $175 \mathrm{kN}$, full geometrical definition of the desired product shape is achieved without any changes by increasing press force. No wrinkles appeared despite the relatively soft rubber material.

After reaching full process feasibility on the 40 Shore rubber pad, additional tests are performed on the 60 and 80 Shore hardness pads at the same press force of $175 \mathrm{kN}$ (see Fig. 8). 
Table 4 Calibration parameters of the optical metrology system gom ATOS core 200

\begin{tabular}{lll}
\hline Parameter & Value & Unit \\
\hline Ambient temperature & 20.0 & ${ }^{\circ} \mathrm{C}$ \\
Warm up time & 15 & minutes \\
Focal length & 12.5 & $\mathrm{~mm}$ \\
Gray value compensation factor & 0.08 & - \\
Number of calibration points & 1911 & - \\
Nominal edge length of calibration plate (square type CP40-200) & 250 & $\mathrm{~mm}$ \\
\hline
\end{tabular}

Harder pads, in general, offer the opportunity to suppress wrinkles [31] and are associated with higher durability [11]. The experiments demonstrate that the cavity is filled incompletely by the harder rubber pads, thus higher process forces would be necessary if an operation of these pads was desirable.

\subsection{Process sensitivity of AM-RPF}

The experiments are conducted under quasi static conditions at an ambient room temperature of $19.5^{\circ} \mathrm{C}$. The corresponding drawing speed of the rubber pad forming experiments is kept constant at $0.3 \mathrm{~mm} / \mathrm{s}$. However, as polyurethane rubber pads are known to reveal considerable high friction coefficients [11], an elevated surface temperature of the sheet metal pieces is expected after forming. Therefore, a variation of drawing speed is conducted under the aforementioned standard conditions (40 Shore hardness rubber pad, $175 \mathrm{kN}$ press force, room temperature) and the surface temperature is recorded at $50 \mathrm{~Hz}$ directly after forming by an infrared camera (InfraTec, type ImageIR $\left.{ }^{\circ} 8360\right)$. To enable these measurements under reliable emission coefficients, the corresponding sheet metal blanks are spray colored matte black with graphite-based paint. After forming and swift opening of the forming tool, the temperature is captured within four circular averaging areas at the flange and dome of the specimens (see Fig. 9). The drawing speed is raised in four steps between 0.3 and 8.1 $\mathrm{mm} / \mathrm{s}$, while the opening speed is identical in all cases (machine maximum of $10 \mathrm{~mm} / \mathrm{s}$ ).
In addition to the investigations on the temperature influence of the process, strain is optically measured by the ViALUX AutoGrid system from exemplary specimens. For this purpose, the blank surfaces are gridded in an electrolytical approach by a $1 \mathrm{~mm}$ square pattern prior to forming. After subjecting to the AM-RPF process, parameterized as mentioned above, the deformed surface of the specimens is captured by four spatially arranged cameras. The images are processed and correlated by a computer software to obtain strain maps. The surface captured strain values are referenced to the blank's mid plane to eliminate bending aspects of the process, which would otherwise show exaggerated values in the fillet radius. The obtained qualitative results are presented in Fig. 10.

Compared to the sheet metal material's ductility given by means of the mechanical parameters listed in Table 3, the specimens are subjected to moderate and uncritical straining in the AM-RPF forming of this geometry.

\subsection{SERIAL PROdUCtion OF SMALL BATCH SIZE}

After these initial studies of the AM-RPF process, a batch size of 64 parts is formed in a sequence on a second, identical and unused AM tool from PLA. The afore mentioned parameters of the RPF process are used throughout the series, i.e., $175 \mathrm{kN}$ of forming force and 40 Shore-A rubber pad hardness. Within an exponential approach, the utilized die is scanned by the gom ATOS core system after zero up to 64 parts to evaluate the influence of any plastic deformation or attrition of the tool on the products.
Fig. 7 Results from the optically measured shapes of the formed pieces as a function of process parameters. A successive increase of process force shows the geometrical definition of the part in the rubber pad forming process. While the apex of the dome was reached after $100 \mathrm{kN}$, larger forces are required to calibrate the radius of the dome-shaped part
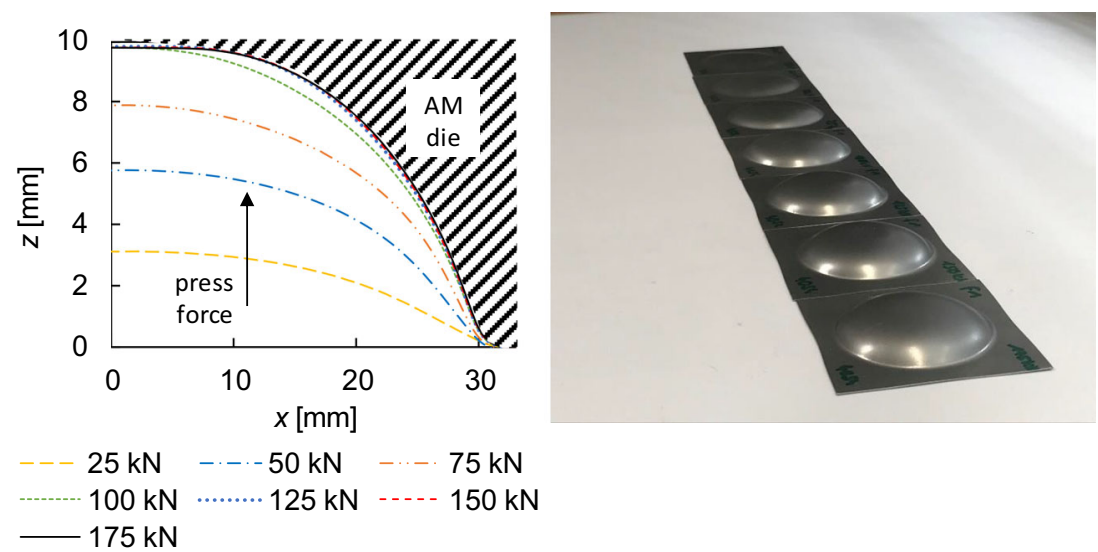
Fig. 8 Results from the optically measured shapes of the formed pieces as a function of process parameters. Variation of shore hardness of the rubber pad, each at the same press force of $175 \mathrm{kN}$

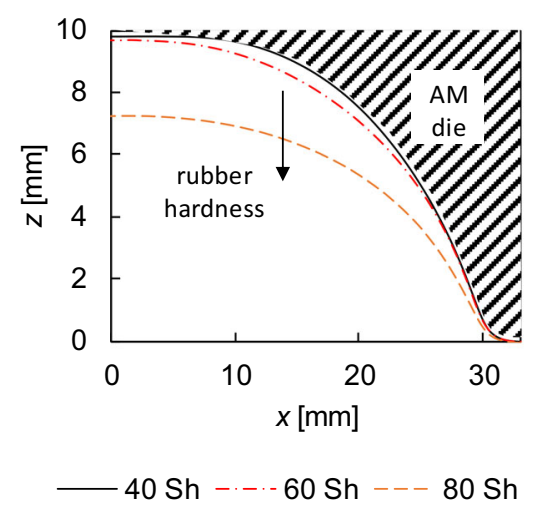

The CAD file of the tooling is compared with the PLA die in its unused state (i.e., subsequently to additively manufacture) by an optical scan in Fig. 11. The analysis indicates the distortion of the geometry. The highest shrinkage of the solid infill pattern indicates deviations at the radius inlet of the cavity of approximately $0.12 \mathrm{~mm}$.

Even though shrinkage is common for FDM printed parts, since the cooling process lowers the specific volume, PLA reveals less shrinkage, compared to ABS and therefore better geometric accuracy $[32,33]$.

After this initial comparison, the die is investigated after punch stroke one and 64 respectively. For this purpose, best- fit comparisons are carried out with the gom software. Fig. 12 depicts the spatial deviation for the unused die and the worn dies.

A systematical circular deviation at the drawing radius can be observed, which most likely results from a permanent deformation and/or wear of the die material. By qualitative and quantitative means, this deviation increases over the number of press strokes and is therefore evaluated in a detailed statistical approach in the following section.

Following the same approach, the ejected blanks are examined up to 64 parts and each compared to the as-manufactured state of the tool surface. Figure 13 indicates the spatial
Fig. 9 Investigation of the influence of forming speed on surface temperature raise of sheet metal due in the AM-RPF process. Infrared examination of the specimens directly after opening the tool with a forming speed of a $0.3 \mathrm{~mm} / \mathrm{s}$ and b $8.1 \mathrm{~mm} / \mathrm{s}$ (false color scale ranging from 18 (dark blue) to 23 (pink) degrees Celsius. c Surface temperatures at the spherical dome (C4) show a very slight cooling over the recording time of the infrared video. $\mathbf{d}$ The trends of surface temperature over drawing speed at each of the four circular evaluation areas indicate an insignificant raise of temperature caused by the process

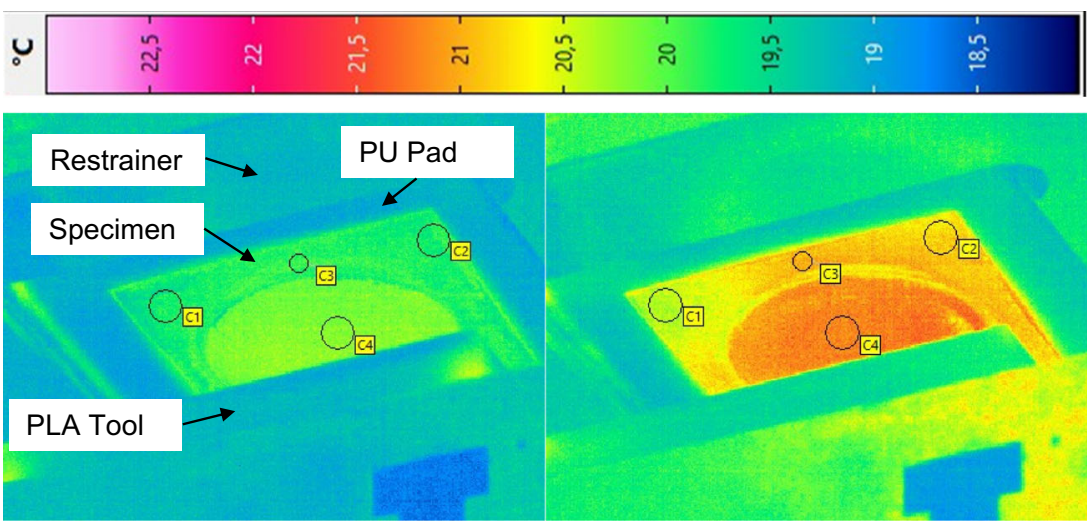

a)

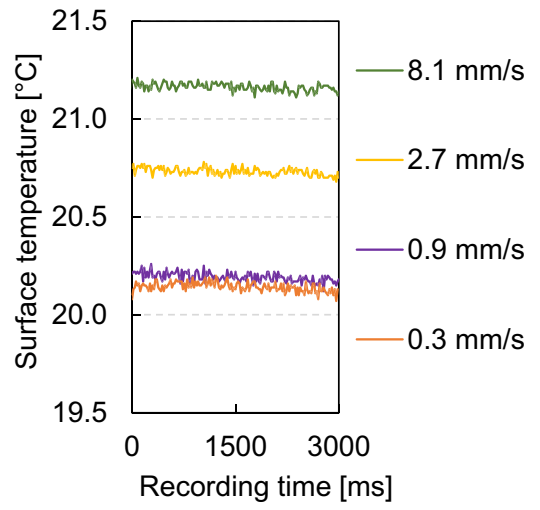

c)

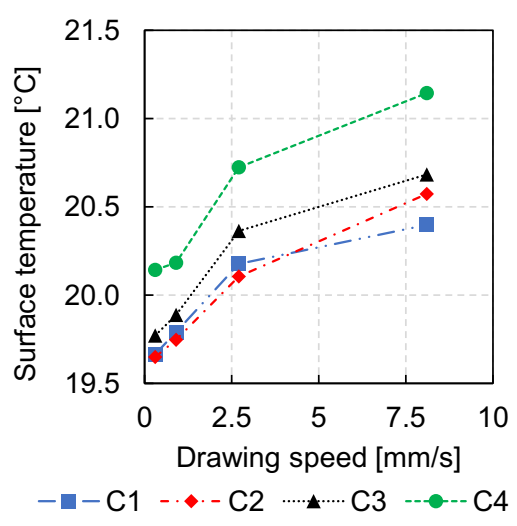

d) 
Fig. 10 Strain maps, as captured from the gridded bottom surface of the formed specimen, are recalculated for the sheet metal's central plane and show a larger strain values caused by drawing in the area of the fillet radius and b stretch drawing aspects of the process in the apex of the dome, which are identified by positive values of minor strain

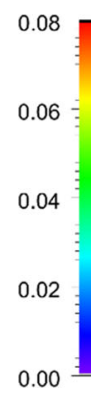

a)

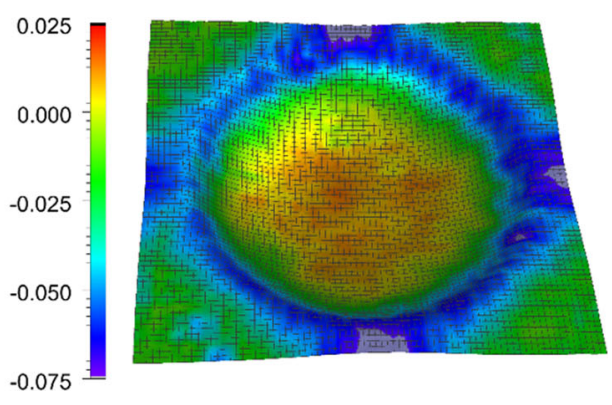

b) deviation showing the first and the last blank part of the batch, which are correlated with the die surface.

Similar to Fig. 12, the sheet metal part left hand side of Fig. 13 indicates the surface of the part obtained from the first press stroke while the right image displays the deviation plot of a blank after 64 punches. By qualitative means, an increasing deviation over the batch can be stated at the floor radius from flange to dome. Highly concentrated contact pressures in this area are caused by the drawing process. Moreover, a deviation area within the tool cavity between die and sheet metal is caused by elastic springback and indicated by blue hues. From the plots, an average offset of $0.3 \mathrm{~mm}$ is obtained for springback.

\subsection{QUALITY ASSESSMENT}

\subsubsection{Blanks}

To evaluate the mechanical integrity of AM tools within a sheet metal drawing process in the context of a small batch size, a statistic evaluation for the blank parts is carried out. For this purpose, cutting planes are established with the help of the gom system to aggregate multiple measurements to obtain a statistic key figure system. The statistic values base on equidistant measurement points with a distance of $2.72 \mathrm{~mm}$ in circumference direction around the drawn cavity. This circle of measurement points is examined at the height of $0.3 \mathrm{~mm}$ above the flange level so the drawn radii of the formed blanks are intersected. The calculated spatial distance of the blank parts is correlated to the unused, as-manufactured die scan. The results from these metrological evaluations are presented in Fig. 14.

In the box plots of Fig. 14, the boxes show the range in between the 1 st and 3rd quartiles, denoted interquartile range IQR, with lines in between to indicate the medians. The whiskers indicate 1.5 times the IQR below the 1 st and above the 3 rd quartiles. Flier points outside the range of the whiskers are considered outliers and indicated as circles. The median of the shape deviation of the fabricated specimens initially strongly increases from the first part starting at $0.041 \mathrm{~mm}$ up to
Fig. 11 Spatial correlation comparing the CAD geometry and the unused die from PLA directly after its additive fabrication by FDM. Symmetric deviations of up to $0.12 \mathrm{~mm}$ are obtained within the tool cavity and related to thermal shrinkage of the fabrication method

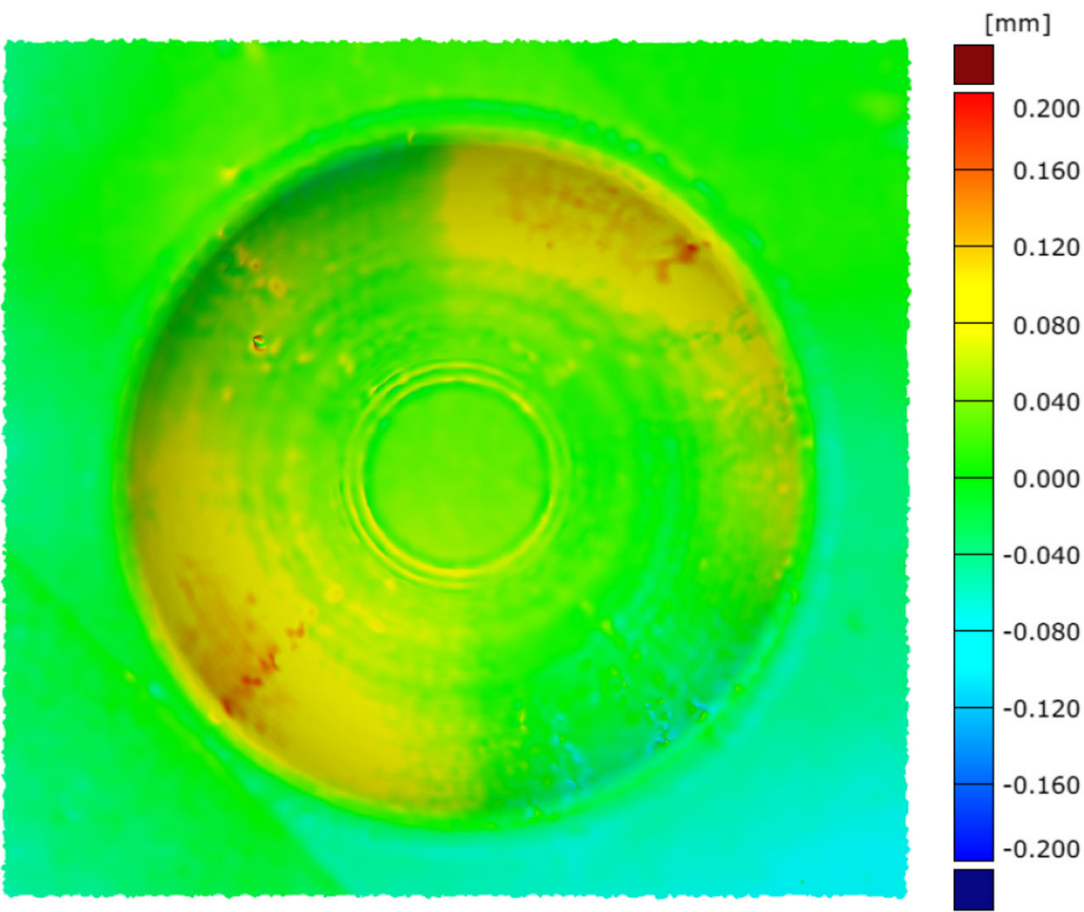



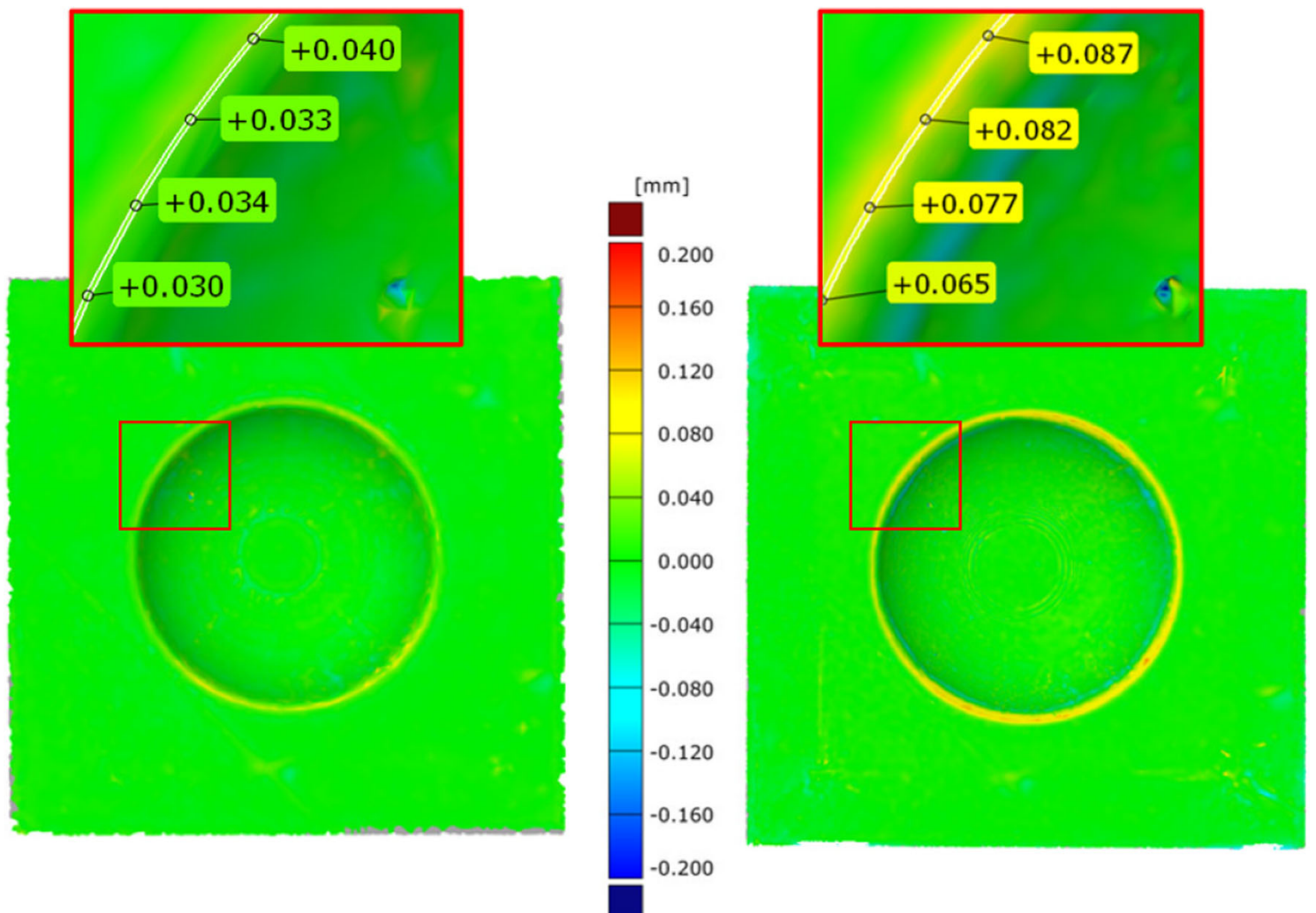

Fig. 12 Optical surface correlation of the unused die subsequently to fabrication and of the die after the first (left) and the 64th press stroke (right). Top brackets indicate equidistant deviation flags at the radius

$0.103 \mathrm{~mm}$ at the third part. After that, the values of the median asymptotically converge toward a constant value of $0.15 \mathrm{~mm}$.

\subsubsection{Tool}

Similar to the evaluation of the sheet metal parts, a quantitative evaluation is conducted for the die surface after representative strokes to ensure the similarity of the deformation in the drawing radius. The measurements are obtained from a cutting plane $0.3 \mathrm{~mm}$ above the flange level delivering a circular evaluation with equidistant points that describe the spatial deviation in between the unused die and its surface after each respective number of strokes (cf. Fig. 12). Figure 15 visualizes the statistical examination of the optical measurements from the die throughout the production of the small batch series.

For the medians of the optical scans of the die surface as a function of part number, a similar trend can be observed. Asymptotically reaching a deviation of $0.05 \mathrm{~mm}$ in median, the absolute values of the deviation are approximately three times smaller compared to the blanks. In contrast to sheet metal forming in conventional dies from tool steel, this observation can be explained by the large difference in the elastic moduli and yield strengths of the herein used polymer-based die in relation to the formed sheet metal blanks. inlet, which will be used for further statistical evaluation. By qualitative manners, the spatial deviation in the drawing radius of the PLA die increases over forming cycles

\section{Discussion}

The small batch series of sheet metal parts produced for the presented study demonstrates the feasibility of the presented AM-RPF process. The major influences on the formation of geometry are demonstrated with regard to applied press force and rubber pad hardness. Due to the local contact pressure distribution caused by the forming operation, an early running in of the drawing radius of the die is observed, which is interpreted as initial plastic flattening of the comparably soft polymer material. With a degressive trend, the deformation stabilizes with the 16th part. In a use-case, this effect could be compensated by a larger drawing radius to equalize the peak of contact stress or even by metallic inserts, such as described by [19].

The selected material PLA - being one of the most common polymers used in the FDM manufacturing processshows suitable mechanical properties under compressive load, with regard to its elastic modulus, as well as to its yield point. Comparable properties are also obtained from the compression tests on PETG, while the mechanical properties of ABS are rated as too weak for the current application. Moreover, PLA has revealed reasonable integrity to withstand the applied press force of $175 \mathrm{kN}$ without breakage, even if heavily loaded areas such as the drawing radius can potentially deform. Further research on higher batches and the material's wearing 


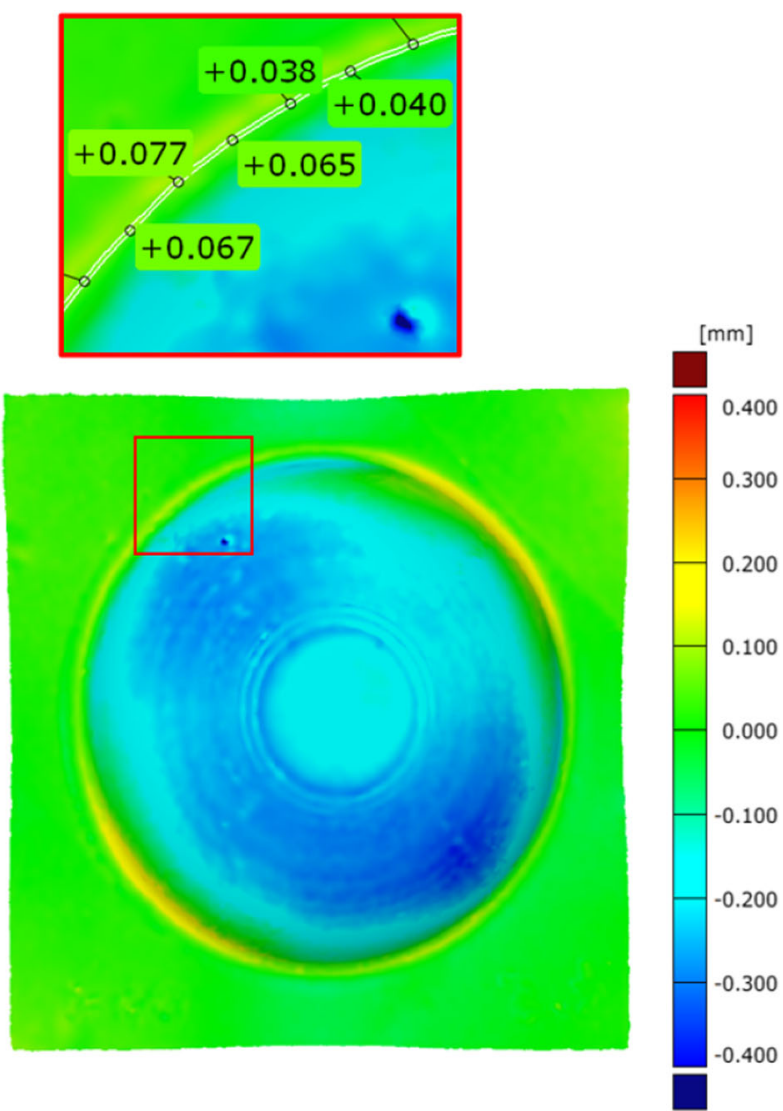

Fig. 13 Optical surface correlation of the unused die subsequently to fabrication and of the first (left) and the 64th sheet metal part (right). Top brackets indicate equidistant deviation flags at the radius inlet, which

behavior when in repetitive sliding contact to metals would therefore be rewarding to extrapolate the applicability of the considered process. In the present investigations, a minor raise
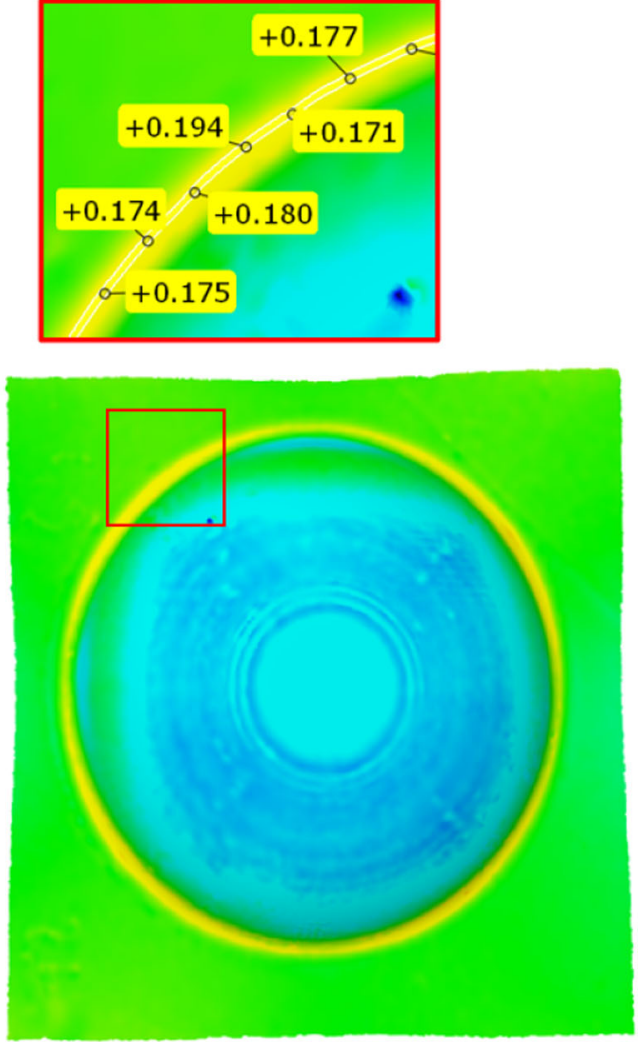

will be used for further statistical evaluation. Over forming cycles, the spatial deviation in the drawing radius of the part increases accordingly to the deviations observed from the die

of surface temperature was detected, i.e., $1.5^{\circ} \mathrm{C}$ at a forming velocity of $8.1 \mathrm{~mm} / \mathrm{s}$. PLA is known to significantly soften at a temperature of roughly $60{ }^{\circ} \mathrm{C}$, therefore a validation of the
Fig. 14 Spatial deviation within the drawing radius for comparing the parts produced by the AMRPF process to the asmanufactured unused die. Statistical evaluation of a small batch series of metal parts indicates degressively increasing median deviations up to $0.15 \mathrm{~mm}$, which asymptotically stabilize roughly at the 16th part

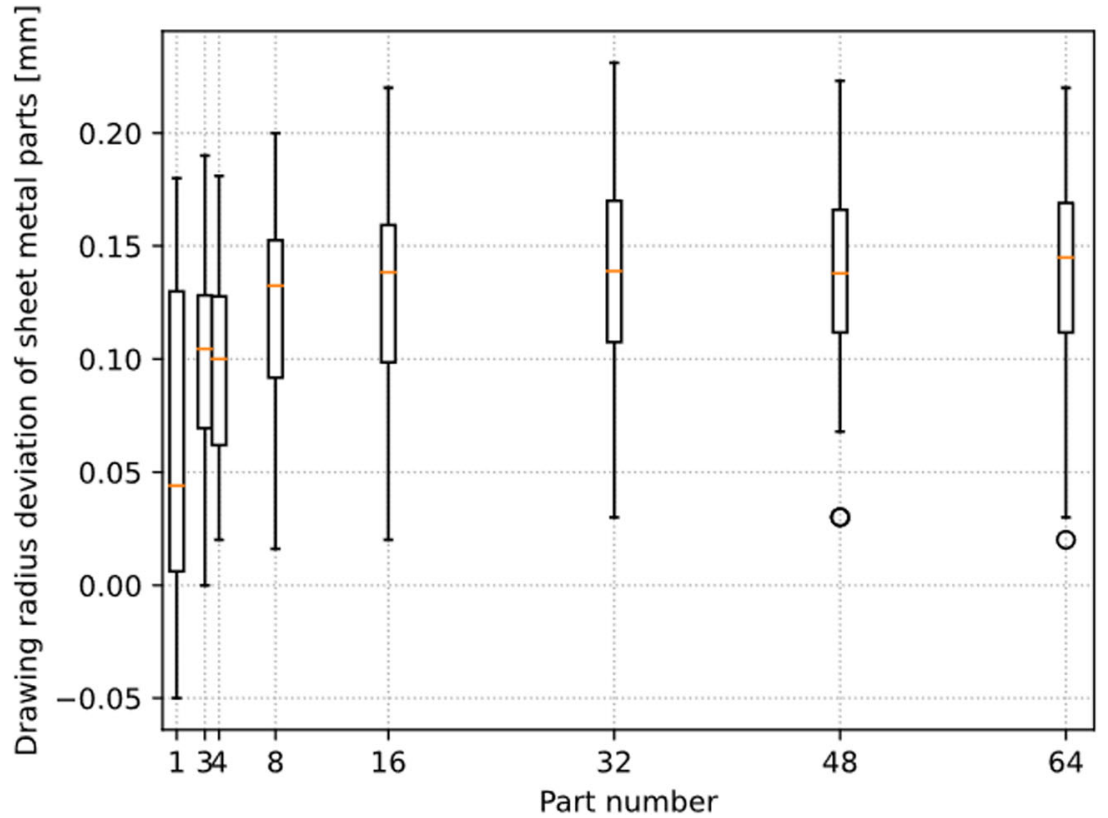


Fig. 15 Spatial deviation within the drawing radius $0.3 \mathrm{~mm}$ above flange plane. Comparison of the as-manufactured unused die to the die throughout the strokes of the AM-RPF process. Statistical evaluation of a small batch series of metal parts indicates degressively increasing deviations up to $0.05 \mathrm{~mm}$

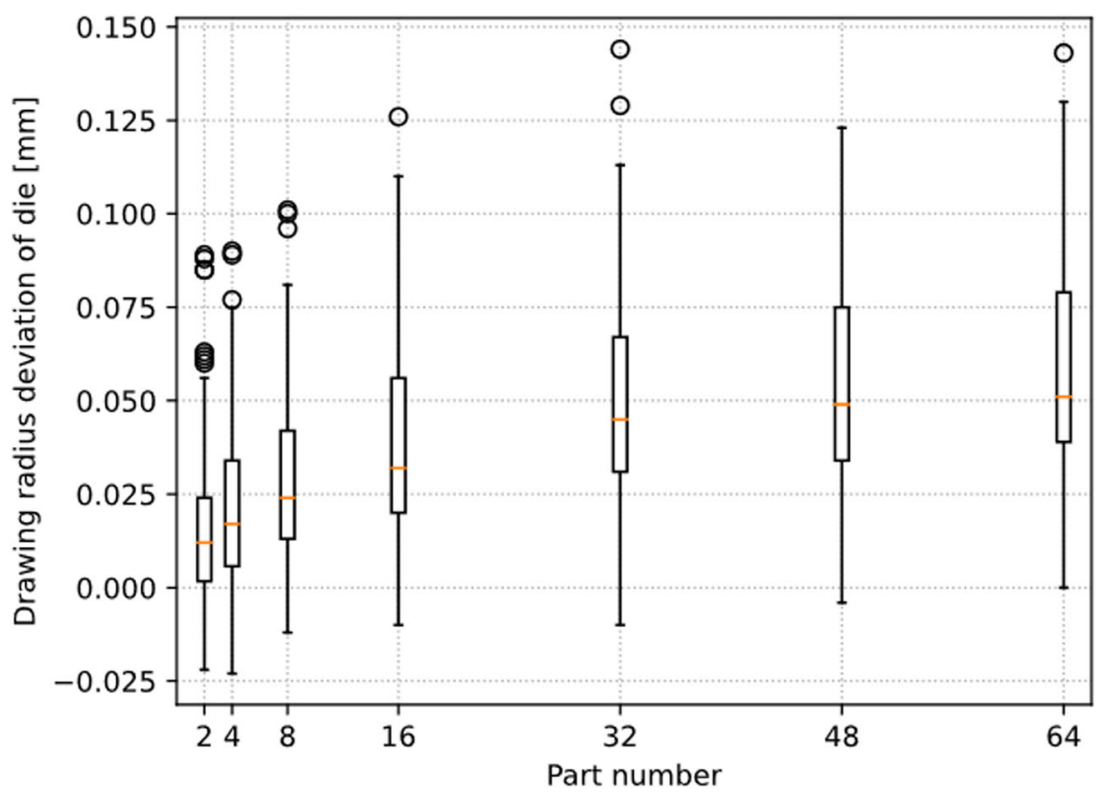

process on a production machine, i.e., a forming press, should be conducted in follow-up studies. Moreover, a preliminary experiment on a polyjetted material with considerably higher strength (Keyence AR-H1) of $\sigma_{\mathrm{y}}=106 \mathrm{MPa}$ resulted in die breakage after $90 \mathrm{kN}$ press load in the presented AM-RPF process due to the material's brittleness. However, when considering a wider spectrum of available polyjetting materials, the general suitability of this AM process for forming tool manufacturing could be of interest.

In addition, a variation of the fillet radius, here $2.5 \mathrm{~mm}$, could reveal reciprocal effects on the processing parameters evaluated in this study. Potentially, the necessary forming force, shore hardness and the surface temperature are suspected to rise with smaller radii and a more pronounced part of stretch forming should be obtained in the process. In turn, a larger fillet radius would cause less pressure localizations and therefore improve the flattening behavior which is observed during the initial parts of the batch production. An improved accuracy may be obtained by avoiding plastic tool deformation.

Compared to conventional forming tools from steel, the elastic constant of the herein objected polymers is a hundredfold smaller. Therefore, springback compensation strategies are required for the purposeful design of drawing dies from polymer materials and should be considered for ongoing research. As obtained from the additive manufacture, a shape deviation of $0.12 \mathrm{~mm}$ is observed comparing the cavity of the die to its CAD model, which is explained by thermal distortion aspects of the FDM process. By incorporating models to describe the residual stresses, as described by [34], thermal shrinkage due to the FDM fabrication process could be compensated. From the correlation of the optical surface scans of the formed sheet metal parts to the die in its state directly after fabrication, a uniform shape deviation of $0.3 \mathrm{~mm}$ is obtained and related to elastic springback of the part after release of press force. In the light of these results, the deviation caused by thermal distortion $(0.12 \mathrm{~mm})$ and the observed trend from the running in effect of the drawing edge $(0.15 \mathrm{~mm})$ could be improved. However, the main influence on deviation between $\mathrm{CAD}$ and product lies at the elastic springback of the sheet metal itself. Springback compensation strategies are well established for sheet metal forming [35] and can be incorporated for future additively manufactured dies.

From an economical point of view, sheet metal forming in additively manufactured dies from polymers could be a rewarding approach for on-demand production of diverse product variants in smaller batch sizes. Conventional drawing tools from steel are costly, primarily due to the aspects of raw material prices for tool steel and therefore related to large and inflexible batches, exclusively. Taking the CAD volume of the die, i.e., $0.349 \mathrm{dm}^{3}$, as a basis, the resulting die costs are twice the price from conventional tool steel, then from PLA or PETG. Moreover, significantly higher fixed costs are related to the machinery of subtractive manufacturing techniques (drilling and milling machines, lathes, etc.) compared to additive manufacturing. While the herein utilized 3D printer is located at the private client end, professional FDM machines, which deliver much shorter manufacturing cycles, still cost a fraction of professional subtractive manufacturing equipment. The rubber pad forming process, in particular, allows to save half of the geometry specific tooling, which is substituted by the elastomer (in this case: the stamp is omitted). Thus, the economical niche of small batches is considered worthy for the application of the approach presented in this study. Restricted availability within a modern production environment - related to optimized occupancy of expensive equipment - will further limit and delay the availability of any subtractive manufacturing facilities. Therefore, due to its lower fixed invest, 3D printing capacities will be faster and 
easier available for tool manufacture. In addition, tools from polymers weigh roughly a fifth of steel tooling which might be another advantage if potential and kinematic energy consumption related to the process cinematics are considered, as well as transportation, equipping, and storing processes. Concluding these aspects, 3D printed forming tools can potentially undercut the invest and lead time for conventional steel tools up to factor 10 and therefore be implemented for producing smaller batch sizes [36].

\section{Conclusions}

Modern production environments are driving the demand for flexible and intelligent production technology, as customer-specific variants are increasingly required [1]. Resource-efficient use of materials affects both the products and the manufacturing processes - but especially the tooling technology used for production when smaller batch sizes become more relevant. Instead of conventional subtractive methods, additive manufacturing techniques can be used to achieve an economical use of lighter and cheaper materials for tools. Compared to steel-based solutions, polymers offer the chance to reduce investment and mass of tooling technology. The fused deposition modeling (FDM) technology is an established process of additive manufacturing (AM), with which complex geometries can be implemented on low-cost production machines. Presently, the extent to which highly stressed forming tools can be manufactured from common 3D printing materials has only been investigated in a few exemplary approaches [36]. The main focus was on costly, unconventional, or nonrecyclable materials [20], concept studies [21], or specific steel inserts at the highly stressed areas [19].

This paper investigates the suitability of a conventional PLA plastic as a material for an additive stretch forming die. Due to its bio-based structure and its possibilities for industrial composting $[37,38]$, a resource-saving approach for producing and potential recycling of forming tools for smaller batch sizes is suggested. The forming tools produced in this way are combined with rubber pad forming (RPF) since this process variant requires only one (positive or negative) instead of two shape-dedicated tool parts compared to deep drawing. The rubber pad forming process in additively manufactured plastic matrices (AM-RPF) is used as an example to produce and evaluate a small series of sheet metal parts. The tools were produced on a Creality Ender 3 Pro 3D printer and then tested in RPF. A $60 \mathrm{~mm}$ diameter dome is produced from a $0.7 \mathrm{~mm}$ thick DC03 type automotive body sheet metal in a series of 64 parts as a demonstrator. In addition to that, the influence of the force and rubber pad hardness on the produced geometry is investigated. Immediately after the 3D printing and, further on, after an exponentially increasing number of press strokes, the PLA drawing die was measured using optical area scans and, likewise, the corresponding sheet metal parts. Therefore, a method for measuring the geometrical quality and accuracy of sheet metal products that are manufactured by additive manufacturing of forming tools is suggested.

The results show that additively manufactured dies from PLA plastic can be used to form conventional car body sheet metals, despite the high process forces involved in this manufacturing operation (17 metric tons press force). An initial flattening was observed at the drawing radius of the die, which is reflected in a form deviation in the radius of $0.15 \mathrm{~mm}$ in the manufactured sheet metal parts. Thermal distortion could be minimized during $3 \mathrm{D}$ printing of the die so that the surface deviations in the cavity of the drawing die are at a maximum of $0.12 \mathrm{~mm}$. The presented process demonstrates that forming tools can be produced from inexpensive, recyclable plastics by additive manufacturing. Combined with the RPF process, the shape-dedicated part of the entire tooling can be reduced so that drawing tools are economically available even for the production of very small lot sizes.

FINAL REMARS An initial manuscript of this study has been published as PrePrint on engrXiv.org [39].

ACKNOWLEDGEMENTS The authors acknowledge the financial support from the European Regional Development Fund (EFRE) within the project SMAPS (grant number: 0200545).

The support in additive manufacturing by Nithin Kumar Padavu from the Chair of Product Development at the University Siegen, as well as Marios Mouratidis in his role as research manager of the Fab Lab at the University Siegen, is highly appreciated. We acknowledge Jonas Knoche's contribution in providing the infrared images.

Availability of data and material Not applicable.

Code availability Not applicable.

Author contribution Not applicable.

Funding Open Access funding enabled and organized by Projekt DEAL. The authors acknowledge the financial support by the European Regional Development Fund (EFRE) within the project SMAPS (grant number:0200545), cf. acknowledgements section.

\section{Declarations}

Competing interests Not applicable.

Open Access This article is licensed under a Creative Commons Attribution 4.0 International License, which permits use, sharing, adaptation, distribution and reproduction in any medium or format, as long as you give appropriate credit to the original author(s) and the source, provide a link to the Creative Commons licence, and indicate if changes were made. The images or other third party material in this article are included in the article's Creative Commons licence, unless indicated otherwise in a credit line to the material. If material is not included in the article's Creative Commons licence and your intended use is not permitted by statutory regulation or exceeds the permitted use, you will need to obtain permission directly from the copyright holder. To view a copy of this licence, visit http://creativecommons.org/licenses/by/4.0/. 


\section{References}

1. Wang Y, Ma H-S, Yang J-H, Wang K-S (2017) Industry 4.0: a way from mass customization to mass personalization production. Adv Manuf 5:311-320. https://doi.org/10.1007/s40436-017-0204-7

2. ElMaraghy HA (2005) Flexible and reconfigurable manufacturing systems paradigms. Int J Flex Manuf Syst 17:261-276. https://doi. org/10.1007/s10696-006-9028-7

3. Maganha I, Silva C, Ferreira LMDF (2019) The layout design in reconfigurable manufacturing systems: a literature review. Int $\mathrm{J}$ Adv Manuf Technol 105:683-700. https://doi.org/10.1007/ s00170-019-04190-3

4. Ersoy K, Celik B (2019) Utilization of Additive Manufacturing to Produce Tools

5. Yang DY, Bambach M, Cao J, Duflou JR, Groche P, Kuboki T, Sterzing A, Tekkaya AE, Lee CW (2018) Flexibility in metal forming. CIRP Ann 67:743-765. https://doi.org/10.1016/j.cirp. 2018.05.004

6. Frohn-Sörensen $P$, Mašek B, Wagner MF-X, Rubešová K, Khalaj O, Engel B (2020) Flexible manufacturing chain with integrated incremental bending and Q-P heat treatment for on-demand production of AHSS safety parts. J Mater Process Technol 275: 116312. https://doi.org/10.1016/j.jmatprotec.2019.116312

7. Schiller M, Heftrich C, Engel B (2021) Remote production. 14th CIRP Conf Intell Comput Manuf Eng 15-17 July 2020 99:242-247. https://doi.org/10.1016/j.procir.2021.03.099

8. Selmi N, Belhadjsalah H (2012) Flexible multipoint hydroforming using metallic sheet medium. https://doi.org/10.13140/RG.2.1. 2761.6889

9. Liu Y, Hua L, Lan J, Wei X (2010) Studies of the deformation styles of the rubber-pad forming process used for manufacturing metallic bipolar plates. J Power Sources - J POWER SOURCES 195:8177-8184. https://doi.org/10.1016/j.jpowsour.2010.06.078

10. Thiruvarudchelvan S (1993) Elastomers in metal forming: a review. J Mater Process Technol 39:55-82. https://doi.org/10.1016/09240136(93)90008-T

11. Deladi EL (2006) Static friction in rubber-metal contacts with application to rubber pad forming processes

12. Altan T, Tekkaya AE (2012) Sheet metal forming: fundamentals. ASM International

13. Cezarina A, Costin G-A, Ionel I, et al. (2019) A review on sheet metal rubber-pad forming. https://doi.org/10.35219/tmb.2018.07

14. Spoelstra P, Djakow E, Homberg W (2017) Rubber pad formingefficient approach for the manufacturing of complex structured sheet metal blanks for food industry. 1896:080004. https://doi.org/ 10.1063/1.5008084

15. Ramezani M, Ripin ZM (2012) Rubber-pad forming processes, 1st edn. Woodhead

16. Elghawail A, Essa K, Abosaf M, Tolipov A, Su S, Pham D (2019) Low-cost metal-forming process using an elastic punch and a reconfigurable multi-pin die. Int J Mater Form 12:391-401. https://doi.org/10.1007/s12289-018-1423-6

17. Stampfl J, Hatzenbichler M (2014) Additive manufacturing technologies. CIRP Encycl Prod Eng:20-27. https://doi.org/10.1007/ 978-3-642-20617-7 6492

18. Thompson MK, Moroni G, Vaneker T, Fadel G, Campbell RI, Gibson I, Bernard A, Schulz J, Graf P, Ahuja B, Martina F (2016) Design for additive manufacturing: trends, opportunities, considerations, and constraints. CIRP Ann 65:737-760. https:// doi.org/10.1016/j.cirp.2016.05.004
19. Nakamura N, Mori K, Abe Y (2020) Applicability of plastic tools additively manufactured by fused deposition modelling for sheet metal forming. Int J Adv Manuf Technol 108:975-985. https:// doi.org/10.1007/s00170-019-04590-5

20. Durgun I (2015) Sheet metal forming using FDM rapid prototype tool. Rapid Prototyp J 21:412-422. https://doi.org/10.1108/RPJ-012014-0003

21. Schuh G, Bergweiler G, Bickendorf P, Fiedler F, Colag C (2020) Sheet metal forming using additively manufactured polymer tools. Procedia CIRP 93:20-25. https://doi.org/10.1016/j.procir.2020.04. 013

22. Biofabrication and 3D tissue modeling (2019)

23. Pappu A, Pickering KL, Thakur VK (2019) Manufacturing and characterization of sustainable hybrid composites using sisal and hemp fibres as reinforcement of poly (lactic acid) via injection moulding. Ind Crop Prod 137:260-269. https://doi.org/10.1016/j. indcrop.2019.05.040

24. Niknejad A, Rezaee N, Asl FJ (2015) Experimental investigation of Teflon-pad forming on circular metal blanks using a concave die. J Manuf Process 20:282-290. https://doi.org/10.1016/j.jmapro.2015. 07.001

25. Szykiedans K, Credo W, Osiński D (2017) Selected mechanical properties of PETG 3-D prints. Procedia Eng 177:455-461. https://doi.org/10.1016/j.proeng.2017.02.245

26. Rodríguez-Panes A, Claver J, Camacho AM (2018) The influence of manufacturing parameters on the mechanical behaviour of PLA and ABS pieces manufactured by FDM: a comparative analysis. Materials 11:1333. https://doi.org/10.3390/ma11081333

27. Musioł M, Sikorska W, Janeczek H, Wałach W, Hercog A, Johnston B, Rydz J (2018) (Bio)degradable polymeric materials for a sustainable future - part 1. Organic recycling of PLA/PBAT blends in the form of prototype packages with long shelf-life. Waste Manag 77:447-454. https://doi.org/10.1016/j.wasman. 2018.04.030

28. Kakanuru P, Pochiraju K (2020) Moisture ingress and degradation of additively manufactured PLA, ABS and PLA/SiC composite parts. Addit Manuf 36:101529. https://doi.org/10.1016/j.addma. 2020.101529

29. Chaitanya S, Singh I (2017) Processing of PLA/sisal fiber biocomposites using direct- and extrusion-injection molding. Mater Manuf Process 32:468-474. https://doi.org/10.1080/ 10426914.2016.1198034

30. del prete A, Papadia G, Manisi B (2011) Computer aided modelling of rubber pad forming process. Key Eng Mater 473:637-644. https://doi.org/10.4028/www.scientific.net/KEM.473.637

31. Thiruvarudchelvan S (2002) The potential role of flexible tools in metal forming. J Mater Process Technol 122:293-300. https://doi. org/10.1016/S0924-0136(02)00077-8

32. Rosli AA, Shuib RK, Ishak KMK, et al. (2020) Influence of bed temperature on warpage, shrinkage and density of various acrylonitrile butadiene styrene (ABS) parts from fused deposition modelling (FDM). 020072. https://doi.org/10.1063/5.0015799

33. Abeykoon C, Sri-Amphorn P, Fernando A (2020) Optimization of fused deposition modeling parameters for improved PLA and ABS 3D printed structures. Int J Lightweight Mater Manuf 3:284-297. https://doi.org/10.1016/j.ijlmm.2020.03.003

34. Li H, Wang T, Li Q, Yu Z, Wang N (2018) A quantitative investigation of distortion of polylactic acid/PLA) part in FDM from the point of interface residual stress. Int J Adv Manuf Technol 94:381395. https://doi.org/10.1007/s00170-017-0820-1

35. Takalkar A, Babu MCL (2018) A review on effect of thinning, wrinkling and spring-back on deep drawing process. Proc Inst 
Mech Eng Part B J Eng Manuf 233:1011-1036. https://doi.org/10. 1177/0954405417752509

36. Schuh G, Bergweiler G, Fiedler F, et al. (2019) A review on flexible forming of sheet metal parts. https://doi.org/10.1109/IEEM44572. 2019.8978879

37. Durucan C, Brown PW (2001) Biodegradable hydroxyapatitepolymer composites. Adv Eng Mater 3:227-231. https://doi.org/ 10.1002/1527-2648(200104)3:4<227::AID-ADEM227>3.0.CO;21

38. Musioł M, Sikorska W, Adamus G, Janeczek H, Richert J, Malinowski R, Jiang G, Kowalczuk M (2016) Forensic engineering of advanced polymeric materials. Part III - Biodegradation of thermoformed rigid PLA packaging under industrial composting conditions. Waste Manag 52:69-76. https://doi.org/10.1016/j. wasman.2016.04.016

39. Frohn-Sörensen P, Geueke M, Belay TT, et al. (2020) 3D printed prototyping tools for flexible sheet metal drawing. https://doi.org/ 10.31224/osf.io/w8rgb

Publisher's note Springer Nature remains neutral with regard to jurisdictional claims in published maps and institutional affiliations. 